\title{
On the Attraction Gap between Chinese and US Movie: From the Perspective of the Audience
}

\author{
Dongjin Yang, Biying Liu \\ Management School, Jinan University, Guangzhou, China \\ Email: yang.dongjin@163.com
}

How to cite this paper: Yang, D.J. and Liu, B.Y. (2017) On the Attraction Gap between Chinese and US Movie: From the Perspective of the Audience. Open Journal of Social Sciences, 5, 17-23.

https://doi.org/10.4236/jss.2017.52003

Received: January 9, 2017

Accepted: January 22, 2017

Published: January 25, 2017

Copyright $\odot 2017$ by authors and Scientific Research Publishing Inc. This work is licensed under the Creative Commons Attribution International License (CC BY 4.0).

http://creativecommons.org/licenses/by/4.0/

\begin{abstract}
This article studies the attraction gap between Chinese and US movie from the perspective of the audience. By employing analysis model of movie attraction, questionnaire and quantitative analysis, this paper explores gaps between Chinese and US movies, and discusses the reasons for forming these gaps. The findings demonstrate that: 1) there are perceived value gaps between Chinese and US movie, 2) on the item level, the larger gaps are truth revelation, sensitive topics, mind purification, mental harvest, friends' praise, unexpectedness, logic, representative, fascination, and 3) on the factor level, the larger gaps are satisfaction of curiosity, plot and moral education.
\end{abstract}

\section{Keywords}

Chinese Movie, US Movie, Movie Attraction, Motion Picture

\section{Introduction}

In Chinese mainland market, the box office of Chinese movies has the trend to catch up and surpass the US in recent years. However, the audience still thinks there is a big gap between Chinese movies and US movies. For example, after watching the movie Avatar, some viewers said: as far as technology is concerned, the Chinese movie is 50 years behind the United States, as for the concept, 100 years. To a certain extent this statement is kidding, but many people agree with this argument.

While US and Chinese movies have been the main topics in Chinese movie studies [1], scarce attention has been devoted to understanding the attraction gap between Chinese and US movie from the perspective of the audience. Existing literature manifests that, the gap between Chinese and US movies embodies in several aspects: political system [2], political education function [3], ideology [4], core value view [5] [6], movie censorship [4], operating mechanism [4] and 
hero characterization [6]. According to their analysis, the reasons for these presented gaps lie not only in the surface layer, but also in the deep layer. Moreover, the perspective of their analysis is different, such as industrial economics, art, sociology and institutional economics.

Actually, no matter what level or what point of view is the gap between the Chinese and US movies, the most fundamental gap is the gap to create attractive ability of movie. Evidence reveals that, no matter the movie from what kind of industry system or ideology, regardless of their educational function, core values, hero characterization, what they eventually present to the audience is one kind of comprehensive attractions, and it is just this attraction, fundamentally determines the box office, the recognition and dissemination range [7] [8] [9]. As such, aiming for more insightful findings, we attempt to use an analytical model [10] established by adopting "movie attraction", a concept that blurs the borderline among economics, communication and management, to analyze the gaps between Chinese and US movies from the perspective of the audience.

\section{Analytical Model of Movie Attraction}

As per Yang and Zhong, movie attraction is defined as the capacity and possibility for movies to attract viewers and satisfy their expectations [10]. Hence, movie attraction is closely linked to the audience's subjective feelings and objective income. As shown in Table 1, the movie attraction includes 5 factors and each factor with 3 items. As a special commodity, films still share the three properties of general merchandise [11]. Moral education, entertainment and satisfaction of curiosity are the essence of films which can cater to the internal demands of customers; plot is the form of films which serves as the carrier of the realization of film's functions; reputation is the extension that guarantees the quality of films.

Table 1. Analytical model of movie attraction and data $(\mathrm{N}=186)$.

\begin{tabular}{|c|c|c|c|c|}
\hline Factor & Item & Chinese movie & US movie & Gap \\
\hline \multirow{3}{*}{ Moral education } & Mental harvest & 3.11 & 4.97 & 1.86 \\
\hline & Mind purification & 2.85 & 4.73 & 1.88 \\
\hline & Inspiration & 3.50 & 3.76 & 0.26 \\
\hline \multirow{3}{*}{ Plot } & Unexpectedness & 2.72 & 4.47 & 1.76 \\
\hline & Logic & 3.27 & 4.75 & 1.48 \\
\hline & Fascination & 3.32 & 4.64 & 1.32 \\
\hline \multirow{3}{*}{ Satisfaction of curiosity } & Truth revelation & 2.34 & 4.72 & 2.38 \\
\hline & Sensitive topics & 2.35 & 4.44 & 2.09 \\
\hline & Information acquisition & 3.55 & 4.42 & 0.87 \\
\hline \multirow{3}{*}{ Entertainment } & Spiritual enjoyment & 3.73 & 4.23 & 0.50 \\
\hline & Relaxation & 3.73 & 4.21 & 0.48 \\
\hline & Emotional appeal & 4.20 & 3.98 & -0.22 \\
\hline \multirow{4}{*}{ Reputation } & Representative & 3.83 & 5.23 & 1.41 \\
\hline & Friends' praise & 3.15 & 4.99 & 1.85 \\
\hline & Social debate & 3.71 & 3.85 & 0.15 \\
\hline & Mean & 3.29 & 4.49 & 1.20 \\
\hline
\end{tabular}




\section{Quantitative Analysis on the Movie Attraction Gap between Chinese and US Movie}

\subsection{Questionnaire and Sample}

Taking the 15 items listed in Table 1 as questionnaire, we asked participants to make their own judgments on the attraction of Chinese and US movies and evaluate the extent to which they agree or disagree with the statements on a sixpoint Likert-type scale ranging from (1) strongly disagree to (6) extremely agree.

The questionnaire statement is: "Overall, the Chinese (or American) film in the following items is very attractive to me". We printed the questionnaires on the front and back of a piece of paper, one side is for the survey of American movies, the other side is for that of Chinese. The respondents are people waiting for admission to the cinema in 4 large cinemas in Guangzhou City. 300 questionnaires were sent out and 271 valid ones were retrieved, yielding a response rate of $87 \%$. To assure good judgment, we eliminated the questionnaires that average annual viewing times are less than 4 , and thus 186 samples remained. The 186 samples: 1) Gender: males accounted for $43.5 \%$ and females $56.5 \%$; 2 ) Age: $19.1 \%$ were under the age of $20,35.2 \%$ were between 21 to $30,24.8 \%$ were at the age of 31 to $40,17.3 \%$ were between 41 to 50 and 3.6\% were above $51 ; 3$ ) Educational Background: $13.0 \%$ were high school graduates, $24.5 \%$ were college students, $47.1 \%$ were undergraduates and $15.4 \%$ were postgraduates.

\subsection{Paired Sample T Test}

As shown in Table 2, the $95 \%$ confidence interval of the difference of perceived value of Chinese and US movie is $(1.65,0.76)$, in other words, no matter what item was randomly selected, we have a $95 \%$ assurance that the gap of the audience' perceived value for Chinese and US movie is between 1.65 and 0.76 .

\subsection{Results of Quantitative Analysis}

1) Overall gap. The Chinese audience' perceived value for Chinese and US movie does exist gap, the mean value of the difference is 1.20 .

2) Gaps of items. We sorted data in Table 1 and formed Figure 1 ( $X$ axis represents item) which shows that, perceived value of Chinese movie is slightly better than US movie in the item of Emotional appeal, and not as good as the US movie in the other 14 items. 9 items' gaps are higher than the mean value of the difference (1.20). They are: truth revelation, sensitive topics, mind purification, mental harvest, friends' praise, unexpectedness, logic, representative, fascination.

Table 2. Paired sample T test of Chinese and US movie $(\mathrm{N}=186)$.

\begin{tabular}{|c|c|c|c|c|c|c|}
\hline \multicolumn{4}{|c|}{$\begin{array}{l}\text { Pair difference } \\
\text { (perceived value of Chinese movie-perceived value of US movie) }\end{array}$} & $\mathrm{t}$ & $\mathrm{df}$ & Sig. \\
\hline Mean & $\begin{array}{l}\text { Standard } \\
\text { deviation }\end{array}$ & $\begin{array}{l}\text { Standard error } \\
\text { of mean }\end{array}$ & $\begin{array}{l}95 \% \text { confidence interval } \\
\text { of the difference }\end{array}$ & -5.79 & 14 & 0.00 \\
\hline 1.20 & 0.81 & 0.21 & $(1.65,0.76)$ & & & \\
\hline
\end{tabular}


3) Gaps of factors. We sorted data in Table 1 and formed Figure 2 (X axis represents factor). In Figure 2, all the 5 factors' perceived value of Chinese movie is not as good as that of the US movie, the degree of factor gap is gradually decreasing from left to right, according to the value of the gap, the 5 factors are: Satisfaction of curiosity, Plot, Moral education, Reputation, Entertainment.

\section{Analysis on the Reasons for the Gap between Chinese and US Movies}

\subsection{Satisfaction of Curiosity}

The gap of this factor mainly embodies in Truth revelation and Sensitive topics (see Table 1). Surface reasons are: Chinese movies avoided modern subject and sensitive topics such lead to deficiency in reflection of the reality and revelation of the truth. So, Chinese movies could not satisfy the audience's peep psychology and curiosity. The deep reasons are closely related to the censorship of the Chinese movie. Political security led Chinese movie loss the ability to reflect reality, to generate empathy, to raise resonation. As a result, the perceived value in this factor decline. The United States has a movie rating system, its censorship mainly embodies in rating rather than politics. Coupled with the pressure of commercial competition, US movie dare to reflect the hot spots, track public events, expose the truth, critique reality. No matter how the US movie style changes, often can they reflect the social trend of though, in response to the audience's inner expectations.

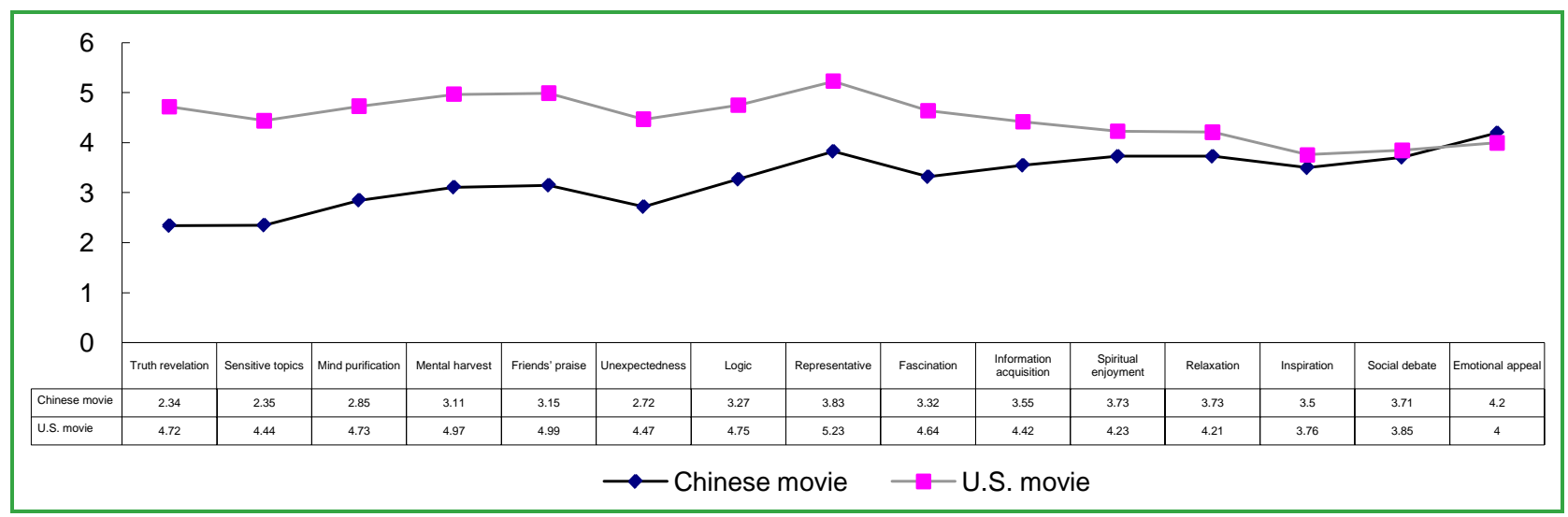

Figure 1. Gaps of 15 items' perceived value of movie attraction.

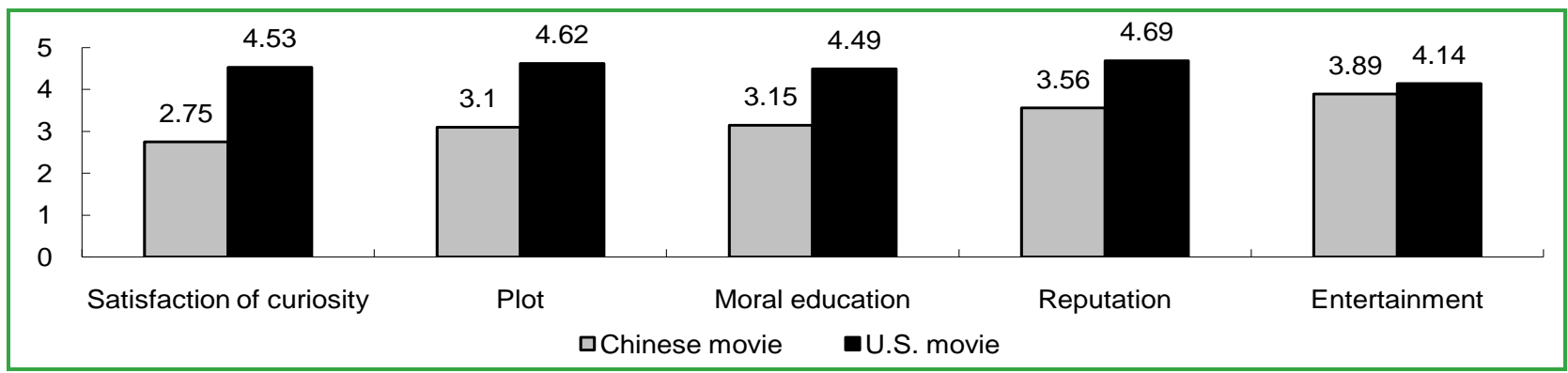

Figure 2. Gaps of 5 factors' perceived value of movie attraction. 
The scarcity value of the realistic criticism gets some evidence from the popularity of Avatar and Let the bullets fly. The audience "see" the brutal demolition from Avatar, the social chaos from Let the bullets fly. When legitimate demands are not met, the audience will seek substitute in a tortuous way. In such cases, it is better to take the initiative to solve rather than to make the audience "distorted". In 2014, movie Coming home directed by Zhang Yimou released. Although its reflection of reality discounted compared to the original, it attracted a large number of middle-aged and old people to return to the theater due to its breakthrough in the subject matter. This is an example of the attraction of selected topic.

\subsection{Plot}

Plot factor includes 3 items: Unexpectedness, Logic, Fascination. As shown in Figure 1, perceived value of Chinese movies in these 3 items are all lower than that of US movies. In the various factors that constitute a movie, the audience's most attention is its narration [10]. This can be traced to the fact that China is a country with a good narrative tradition [12]. The audience requires the story not only to be tortuous, fascinating, but also to be reasonable and logical. Contrary to the requirements of the audience, instead of using movies to tell a story, some Chinese mainstream movies turned movies into political propaganda which just representing events. For example, to pursuit historical significance, some revolutionary historical movies often directly express the feeling of personal life in a "grand narrative" way, the individual is compressed and such turned the personal stories which could be shown completely into fragment. In the end, what these movies left to the audience is a few pieces of the memory. On the contrary, Hollywood tends to integrate personal destiny into the grand historical background, narrate the fate of the individual or family logically, and connect magnificent historical process and unstable political situation with individual story organically. Movies such as Schindler's list, Saving Private Ryan, Kung Fu Panda are all of such characteristics.

Apart from the above, Chinese movies lack a sincere attitude towards the movie and the audience and often underestimate the audience's IQ and EQ, even ignore their psychological feelings. On the whole, US movies respect the audience and history or reality and follow the laws of art and communication. In order to get the greatest recognition from the audience, they do everything to study and arrange the story from the audience's perspective. So the plots of US movies are often able to be both logical and unexpected.

\subsection{Moral Education}

If it is excusable that there is a big gap between US movies and Chinese movies in the factors of Satisfaction of curiosity and Plot, then, the big gap in the factor of Moral education (see Figure 2) cannot but embarrass Chinese movie which always attaches great importance to education. The reasons are: First, Chinese mainstream movies often do not try to hide the view and to tell a good story 
with audio-visual language, but to instill political philosophy stiffly, such as The Days Without My Comrade; Second, Chinese commercial movie, like The Banquet, over emphasis on the entertainment and the box office, and such leads to the chaos of value. Killing, violence, sex, etc. has become its essential elements. Overall, the vision of Chinese movie is narrow. Class conflict and ethnic hatred are always its main line of the plot development. Chinese movie ignores or does not dare to face up to the opposition such as humanity and inhumanity, ruling and being ruled, which is more profound, contagious and thrilling. In sum, Chinese movie failed to meet the audience's basic spiritual needs which store in the deep sense and looking forward to be satisfied or eased by appropriating aesthetic object.

Most of the US movies are just the opposite. They (e.g. Forrest Gump, etc.) may deviate, deform, pull away real life variedly or bizarrely, but in the deep level of the spirit structure, they most closely link with the audience's specific needs. In terms of content of expression, US movie expresses human feelings of general concern, shows and taps human nature, reflects the eternal theme of human beings and universal values, so that people from different ethnic groups all could have a strong resonance. In the way of expression, US movie often conceals its national identity, packages itself with various cultural elements from other countries, and makes the audience accept its views in emotion, culture and identity by means of intricate plots and shocking visual effects. Hacksaw Ridge is an excellent example.

\subsection{Reputation}

As seen in Figure 1, the gap in this factor between Chinese and US movie mainly embodies in Friends' praise and Representative, the gap in Social debate is small. On the one hand, US movies have a good reputation in the Chinese audiences, as we can see in Douban movie's online rating system, many US movies, e.g. The Shawshank Redemption, Forrest Gump, Inception, Gone with the wind, stay on the top; on the other hand, in the fields of propaganda, manufacturing hot spots and forming social topics, the threat from US movie is not too large. Part of the reason is localization or cultural discount [13] [14].

\subsection{Entertainment}

The gap in this factor is small, indeed, Chinese movie is slightly better than the US movie (gap is -0.22 , see Table 1 or Figure 1 ) in the item of Emotional appeal. Eliminating the role of cultural discount, the degradation of Chinese movie in Satisfaction of curiosity and Moral education makes entertainment become directors or audience's new orientation consciously or unconsciously, to a certain extent, also narrows the gap.

\section{Conclusion}

From the perspective of movie attraction, there are perceived value gaps between Chinese and US movie. The mean value of the difference is 1.20 (questionnaire 
is on a six-point Likert-type). Chinese movie is not as good as the US movie in truth revelation, sensitive topics, mind purification, mental harvest, friends' praise, unexpectedness, logic, representative, fascination. Or, more generally, US movie outperformed Chinese movie in satisfaction of curiosity, plot, moral education, reputation, entertainment.

\section{References}

[1] Su, W. (2011) Resisting Cultural Imperialism, or Welcoming Cultural Globalization? China's extensive debate on Hollywood cinema from 1994 to 2007. Asian Journal of Communication, 2, 186-201. https://doi.org/10.1080/01292986.2010.539301

[2] Jia, Y. and Shi, Y. (2012) A Talk on the Difference between Chinese and American Movies from the Social Angle. The Sound of the Yellow River, 5, 115.

[3] He, X. (2011) Ideological and Political Education in Movie Media: A Comparative Study of Ideological and Political Education in Chinese and American Movies. Theory Monthly, 6, 180-182.

[4] Cui, Q. (2009) When the Domestic Film Won the Hollywood-On the Differences between Chinese and American Movies. Fiction Review, S2, 232-235.

[5] Zhao, S. (2012) Review and Reflection on Chinese and American Movies. New West (Theoretical Edition), 8, 187-188.

[6] Yuan, S. and Wan, H. (2013) Comparison and Integration of Heroism in Chinese and American Films: Taking Kung Fu Panda and the Flowers of War as Examples. Journal of Shanxi Datong University (Social Science), 3, 62-64, 89.

[7] Gao, X. (2009) On the Structure of Film Attractiveness. Art of Huangmei Opera, 2, 66-67.

[8] Gunning, T. (1986) The Cinema of Attractions: Early Cinema, Its Spectator, and the Avant-Garde. Wide Angle, 8, 3-4.

[9] Gazley, A., Clark, G. and Sinha, A. (2011) Understanding Preferences for Motion Pictures. Journal of Business Research, 8, 854-861.

https://doi.org/10.1016/j.jbusres.2010.09.012

[10] Yang, D. and Zhong, X. (2016) The Perception of Film Attractiveness and Its Effect on the Audience Satisfaction, Intention and Investment. Journal of Service Science and Management, 9, 21-27. https://doi.org/10.4236/jssm.2016.91003

[11] Kotler, B.P. (1973) Marketing Management: Analysis, Planning, Implementation, and Control. Clc., 1, 297-320.

[12] Jia, L. and Jiang, G. (2009) Film: How to Achieve the Correct Cultural Expression. Cultural and Artistic Research, 3, 189-192.

[13] Hoskins, C. and Mirus, R. (1988) Reasons for the US Dominance in International Trade in Television Programs. Media Culture \& Society, 4, 499-504. https://doi.org/10.1177/016344388010004006

[14] Lee, F.L.F. (2006) Cultural Discount and Cross-Culture Predictability: Examining the Box Office Performance of American Movies in Hong Kong. Journal of Media Economics, 4, 259-278. 
Submit or recommend next manuscript to SCIRP and we will provide best service for you:

Accepting pre-submission inquiries through Email, Facebook, LinkedIn, Twitter, etc. A wide selection of journals (inclusive of 9 subjects, more than 200 journals)

Providing 24-hour high-quality service

User-friendly online submission system

Fair and swift peer-review system

Efficient typesetting and proofreading procedure

Display of the result of downloads and visits, as well as the number of cited articles Maximum dissemination of your research work

Submit your manuscript at: http://papersubmission.scirp.org/

Or contact jss@scirp.org 